\title{
Cerebrospinal fluid biomarkers for cognitive disorders. An introductory overview
}

\author{
George P. Paraskevas \\ Division of Cognitive and Movement Disorders and Unit of Neurochemistry and Biological Markers, 1st Department of Neurology, \\ National and Kapodistrian University of Athens, School of Medicine, Eginition Hospital, Athens 11528, Greece. \\ Correspondence to: Dr. George P. Paraskevas, Division of Cognitive and Movement Disorders and Unit of Neurochemistry \\ and Biological Markers, 1st Department of Neurology, National and Kapodistrian University of Athens, School of Medicine, \\ Eginition Hospital, 72 Vas. Sophias Ave, Athens 11528, Greece. E-mail: geoprskvs44@gmail.com
}

How to cite this article: Paraskevas GP. Cerebrospinal fluid biomarkers for cognitive disorders. An introductory overview. Neuroimmuno/ Neuroinflammation 2020;7:183-93. http://dx.doi.org/10.20517/2347-8659.2019.008

Received: 13 Aug 2019 First Decision: 24 Dec 2019 Revised: 11 Mar 2020 Accepted: 18 Mar 2020 Available online: 24 Jun 2020

Science Editor: George P. Paraskevas Copy Editor: Jing-Wen Zhang Production Editor: Tian Zhang

\begin{abstract}
The core (established) cerebrospinal fluid biomarkers of Alzheimer's disease (AD), namely amyloid-beta peptide, total tau protein and phospho-tau protein, have become a part of the diagnostic workup of patients with cognitive disorders in many specialized centers, especially for ambiguous cases. Combined, these biomarkers can identify the presence or absence of an AD biochemical process with sensitivities and specificities approaching or exceeding $90 \%$ in both dementia and pre-dementia stages of AD. Thus, they have been incorporated in various sets of research or clinical diagnostic criteria and recommendations. Results that are atypical, incompatible with $A D$, or inconclusive may occur, necessitating the use of other cerebrospinal fluid or imaging biomarkers.
\end{abstract}

Keywords: Cerebrospinal fluid, tau, phospho-tau, amyloid-beta, Alzheimer's disease, alpha-synuclein, TDP-43, neurofilament light protein

\section{INTRODUCTION}

Almost 25 years after their first introduction, cerebrospinal fluid (CSF) biomarkers have become a part of the diagnostic workup of patients with cognitive disorders in many specialized centers. Furthermore, they provide neurochemical information about the disorder underlying each individual patient's clinical presentation, which currently should be viewed as a biological process, sometimes starting many years prior to symptom onset and gradually evolving into a typical or atypical clinical phenotype. This paper provides an introductory, concise review, regarding the current status and future perspectives of CSF biomarker use.

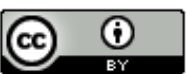

(C) The Author(s) 2020. Open Access This article is licensed under a Creative Commons Attribution 4.0 International License (https://creativecommons.org/licenses/by/4.0/), which permits unrestricted use, sharing, adaptation, distribution and reproduction in any medium or format, for any purpose, even commercially, as long as you give appropriate credit to the original author(s) and the source, provide a link to the Creative Commons license, and indicate if changes were made.

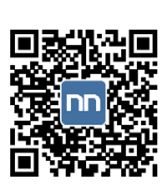




\section{WHY DO WE NEED BIOMARKERS?}

Alzheimer's disease (AD) is the most common type of dementia ${ }^{[1]}$, followed by vascular cognitive impairment $(\mathrm{VCI})^{[2]}$, dementia with Lewy bodies $(\mathrm{DLB})^{[3]}$, frontotemporal dementia (FTD $)^{[4]}$ and others. Until relatively recently, diagnosis of AD was made according to clinically based criteria ${ }^{[5]}$. These criteria may show high diagnostic accuracy, especially when typical cases are examined in specialized centers ${ }^{[6]}$. However, it is long known that in the community, in early, presenile or atypical cases and in the presence of comorbidities, diagnostic accuracy may drop substantially, with clinicopathological concordance rates sometimes as low as $62.5 \%^{[7-9]}$. Furthermore, it is now recognized that $\mathrm{AD}$, typically presenting as an amnestic dementia syndrome, may rarely have frontal (sometimes frontotemporal-like) ${ }^{[10,11]}$, posterior $^{[10,11]}$, language ${ }^{[10-12]}$ and even corticobasal-like presentations ${ }^{[13,14]}$. Thus, the same disease may present with different phenotypes, and one phenotype may be caused by different diseases/pathologies. Mixed pathologies are not infrequent in senile cases ${ }^{[15]}$, especially $\mathrm{AD}$ mixed with various types of vascular lesions ${ }^{[16]}$, or DLB with concomitant AD pathology ${ }^{[17]}$. Such mixed pathologies may modify the clinical presentation ${ }^{[18,19]}$ and the rate of disease progression ${ }^{[20]}$. In addition, some patients present very early, in a symptomatic but pre-dementia stage [mild cognitive impairment (MCI) and MCI due to $A D]^{[21]}$. On the other hand, when the clinical impression is against $\mathrm{AD}$, there is still a $39 \%$ chance for pathological verification of $\mathrm{AD}$ (co)existence ${ }^{[22]}$.

The above are not uncommon causes of diagnostic confusion in everyday practice. Of course, the gold standard for diagnostic verification is post mortem pathological examination. However, correct ante mortem diagnosis is necessary since it may help in predicting prognosis and it is likely to affect therapeutic decisions ${ }^{[23]}$. Thus, biomarkers are needed to serve as objective diagnostic tools during life. In the last 3 decades, various biomarkers have been developed (some being incorporated in various sets of diagnostic criteria), including structural neuroimaging (pattern of atrophy as a marker of neuronal injury), functional neuroimaging with positron emission tomography (PET), either as FDG-PET (hypometabolism as a marker of neuronal injury) or PET at least for amyloid-beta $(\mathrm{A} \beta)$, and CSF biomarkers ${ }^{[10,11]}$. The last have probably received the most attention.

\section{ESTABLISHED (CORE) CSF BIOMARKERS OF AD}

In an oversimplified scheme, there are two biochemical processes and pathological hallmarks of $\mathrm{AD}$ : (1) misfolding, oligomerization and finally polymerization and extracellular aggregation of $A \beta$, in the form of amyloid plaques, and (2) intracellular hyperphosphorylation and polymerization of the microtubule-associated protein tau, forming paired helical filaments which in turn aggregate in the form of neurofibrillary tangles ${ }^{[24,25]}$. The former process mobilizes various mechanisms that are toxic to neurons ${ }^{[26]}$, and the second results in destabilization of microtubules and dysfunction of the cytoskeleton and of axonal transport ${ }^{[27]}$. Both processes, acting synergistically, lead to neuritic, synaptic and neuronal loss, through a vicious circle of interconnecting final pathways of oxidative stress, excitotoxicity, mitochondrial dysfunction, apoptosis and $\mathrm{Ca}^{2+}$-mediated cell death ${ }^{[28-30]}$, while prion-like spread ${ }^{[31]}$ and neuroinflammation ${ }^{[32-34]}$ are increasingly recognized as important early mechanisms.

Total tau protein $\left(\tau_{\mathrm{T}}\right)^{[35]}$, hyperphosphorylated tau, especially at a threonine residue at position $181\left(\tau_{\mathrm{P}-181}\right)^{[36]}$ and $A \beta$ peptide with 42 amino acids $\left(A \beta_{42}\right)^{[37]}$ can be quantified in the CSF. In $A D$, $\tau_{\mathrm{T}}$ is increased, and traditionally, this is viewed as a marker of neuronal/axonal injury ${ }^{[38]} ; \tau_{\mathrm{P}-181}$ is also increased and this is considered a more specific marker of tangle formation ${ }^{[39]}$. On the other hand, $A \beta_{42}$ is decreased and this is considered (inversely) a marker of amyloid burden ${ }^{[40]}$. The above markers are useful in the discrimination of $\mathrm{AD}$ from normal aging and other dementias, and even abnormal $\tau_{\mathrm{T}}$ alone may show high sensitivity and, in a few diagnostic questions, adequate specificity for the diagnosis of $\mathrm{AD}^{[41]}$. Combinations of the above biomarkers in the form of various formulas (including the Hulstaert formula ${ }^{[42]}$ ) or ratios (including $\tau_{\mathrm{T}} / \mathrm{A} \beta_{42}$ or $\tau_{\mathrm{P}-181} / \mathrm{A} \beta_{42}{ }^{[43,44]}$ ) further increase their diagnostic value. 


\section{HOW EARLY DO THE CLASSICAL BIOMARKERS BECOME ABNORMAL?}

Currently, $\mathrm{AD}$ is viewed as a pathological or neurobiological entity, characterized by a continuum of 3 stages, starting as a preclinical ("asymptomatic at risk" or "presymptomatic") stage, which later on progresses to a symptomatic but pre-dementia stage $(\mathrm{MCI})$ and finally to the dementia stage ${ }^{[11,45]}$. It seems that in most cases CSF biomarkers become abnormal during the preclinical stage of $\mathrm{AD}^{[45]}$, and on the basis of studies in families with autosomal dominant AD, this may occur even 10-20 years prior to the expected age of symptom onset ${ }^{[46]}$. In patients with $\mathrm{MCI}$, abnormalities are detected 5-10 years before progression to dementia ${ }^{[47]}$. Usually, the first abnormality detected is a decrease in $A \beta_{42}$, followed by an increase in $\tau_{\mathrm{P}-181}$ and $\tau_{\mathrm{T}}$, but the reverse order may sometimes be observed ${ }^{[45]}$. Sometimes, only the $A \beta_{42}$ decrease is seen in the preclinical stage, and the increase in $\tau_{\mathrm{P}-181}$ and $\tau_{\mathrm{T}}$ is observed in the pre-dementia (MCI) stage of $\mathrm{AD}^{[48]}$. Thus, in the vast majority of patients, all 3 classical biomarkers are already abnormal when patients enter the dementia stage and in many (if not most), at the beginning of the MCI stage as well. CSF levels may continue to change during disease progression ${ }^{[46,48,49]}$. Such changes may be important from the neurochemical point of view, and it has been suggested that they may correlate with the stage of the disease ${ }^{[48]}$. However, from a diagnostic point of view, the changes compared to controls are small, and thus, these biomarkers are considered as state and not stage markers ${ }^{[49]}$.

\section{DEFINITION OF THE ALZHEIMER'S CLASSICAL CSF BIOMARKER PROFILE (SIGNATURE)}

In the research diagnostic criteria for AD of the International Working Group (IWG-2), both decreased $\mathrm{A} \beta_{42}$ and increased tau protein (either $\tau_{\mathrm{T}}$ or $\tau_{\mathrm{P}-181}$ ) are considered as in vivo evidence of AD pathology, with sensitivities and specificities approaching or exceeding $90 \%{ }^{[11]}$. However, more recent recommendations suggest that all 3 biomarkers should be abnormal ${ }^{[50]}$. Indeed, this may increase specificity, and abnormality of all 3 biomarkers is highly suggestive (and specific) of the presence of $\mathrm{AD}$, while normal values of all 3 biomarkers is highly suggestive of the absence of $\mathrm{AD}$ pathology ${ }^{[50]}$. In patients with $\mathrm{MCI}$, the combination of all 3 markers ( $\tau_{\mathrm{T}}$ and the $\mathrm{A} \beta_{42} / \tau_{\mathrm{P}-181}$ ratio) identified those harboring $\mathrm{AD}$ pathology with sensitivities and specificities of $95 \%$ and $87 \%$, respectively ${ }^{[51]}$.

In pathologically verified cases, the combination of $A \beta_{42}$ and $\tau_{\mathrm{T}}$ identified $\mathrm{AD}$ patients, discriminating them from other dementias or controls with sensitivity and specificity of $90 \%$ and $89 \%$, respectively ${ }^{[52]}$, while the combination of $A \beta_{42}$ with the more specific $\tau_{\mathrm{P}-181}$ discriminated $\mathrm{AD}$ from other dementias with sensitivity and specificity of $80 \%-88 \%$ and $93 \%-100 \%$, respectively ${ }^{[52,53]}$.

The above indicates that, ideally, the AD CSF biomarker signature should be defined as abnormal values of all 3 core biomarkers. However, the combination of $A \beta_{42}$ with one of the tau forms (either total or phosphorylated) may be sufficient in everyday practice.

\section{ANSWERED AND UNANSWERED QUESTIONS}

Classical AD biomarkers are useful in everyday practice since they can discriminate AD from normal aging $^{[43]}$ and psychiatric conditions ${ }^{[54]}$. They offer an added diagnostic value in everyday differential diagnosis of dementia patients, since they increase diagnostic confidence ${ }^{[41]}$ and correctly identify the presence or absence of $\mathrm{AD}$ in $82 \%$ of patients with uncertain clinical diagnosis ${ }^{[5]}$. They can be useful in the differential diagnosis between $\mathrm{AD}$ and $\mathrm{FTD}^{[56]}$, and they can identify the additional presence or absence of $\mathrm{AD}$ in patients with cerebrovascular disease and dementia ${ }^{[44]}$, including subcortical small vessel disease ${ }^{[57]}$. These biomarkers may also determine the additional presence of AD in patients with $\mathrm{DLB}^{[58]}$ and those with normal pressure hydrocephalus ${ }^{[59]}$. Additionally, they can identify the presence or absence of AD biochemical process in patients with certain cognitive and/or parkinsonian syndromes such as primary progressive aphasia ${ }^{[12]}$, posterior cortical atrophy ${ }^{[60]}$ and corticobasal syndrome ${ }^{[13]}$. 
Of course, CSF AD biomarkers are not standalone tools, and they should be used in conjunction with clinical, imaging, neuropsychological and other biochemical data to reach the correct diagnosis ${ }^{[11]}$. Keeping that in mind, CSF $A \beta_{42}, \tau_{\mathrm{T}}$ and $\tau_{\mathrm{P}-181}$ fulfill most of the criteria required for valid biomarkers ${ }^{[61]}$, since they reflect key biochemical mechanisms of $\mathrm{AD}$, and combined, they provide sensitivities and specificities greater than $80 \%-85 \%$. Sampling needs lumbar puncture, which is less agreeable than urine or blood sampling. However, it is a minimally invasive procedure, usually well-tolerated and with a low incidence of post-lumbar puncture headache $(<4.5 \%)$ in dementia patients ${ }^{[43,62]}$. Thus, the 3 core CSF biomarkers were gradually incorporated in research and/or clinical diagnostic criteria for $\mathrm{AD}$ in the dementia (typical or atypical presentations $)^{[10,11,63]}, \mathrm{MCI}^{[11,64]}$ and preclinical stages ${ }^{[65]}$, and if testing is available, they are currently considered as part of the diagnostic workup of cognitive disorders, especially in ambiguous cases ${ }^{[6-68]}$. Since new disease-modifying or preventive treatments are currently underway, CSF biomarkers may be used for the selection of patients suitable for clinical trials across all stages of AD (including the preclinical stage) and/or for monitoring treatment effects ${ }^{[69,70]}$.

With time, it has become evident that biomarkers can detect CSF signatures different from the one observed in AD. The term "suspected non-Alzheimer pathophysiology" (SNAP) was introduced for a biomarker profile with normal $A \beta_{42}$ but an abnormal marker of neuronal injury or neurodegeneration, while the term "primary age-related tauopathy" has been used for the tau pathology picture in the medial temporal lobe (hippocampus, entorhinal cortex), with or without minimal $A \beta$ pathology ${ }^{[71]}$. In patients with normal $A \beta_{42}$, the $A \beta_{42} / A \beta_{40}$ ratio may be used to confirm the absence of amyloid abnormality, since it "corrects" observed $A \beta_{42}$ levels for the total level of $A \beta_{40}$ (the most abundant form of $A \beta$ peptide) ${ }^{[67,72]}$. When amyloid normality is confirmed, $\mathrm{AD}$ becomes unlikely ${ }^{[50]}$ and tauopathies, TDP-43 proteinopathies and other pathologies may be considered to explain SNAP cases ${ }^{[73]}$. Controversies and questions concerning the "non-AD" biomarker profiles and the underlying pathologies have led to a modification of the 2011 National Institute on Aging and Alzheimer's Association separate recommendations ${ }^{[1,64,65]}$, to a unified biological definition of AD across all stages and incorporating the various possible biomarker profiles and disease categories (AD or non-AD $)^{[74]}$. This incorporation of "extended" biomarker profiles in diagnostic recommendations, may prove useful in many atypical presentations, including patients resembling or even fulfilling criteria for AD, but without the expected $\mathrm{AD}$ CSF biomarker signature, although biomarker levels may remain conflicting in occasional patients.

Another profile which may be observed is characterized by abnormality (reduction) of only $\mathrm{A} \beta_{42}$, while $\tau_{\mathrm{T}}$ and $\tau_{\mathrm{P}-181}$ being normal. In this case, the $\mathrm{A} \beta_{42} / \mathrm{A} \beta_{40}$ may be used to confirm or exclude amyloid abnormality. If amyloid reduction is confirmed, $\mathrm{AD}$ pathology may be less likely in patients with full-blown dementia, but it is still a possibility, especially in pre-dementia patients ${ }^{[50]}$ and may be compatible with the "AD pathological change" ${ }^{\text {"74] }}$. This profile may also be observed in vascular cognitive decline ${ }^{[57]}$ and in Lewy body synucleinopathies, including PD, PDD and especially DLB ${ }^{[75]}$.

Furthermore, there is always the problem of mixed pathologies, especially in the elderly. In a patient with a clinical picture suggestive of DLB, the identification of the typical AD CSF signature, may indicate mixed synucleinopathy with concomitant $\mathrm{AD}$ pathology ${ }^{[11,76]}$, but cases of $\mathrm{AD}$ with unusual DLB-like presentations have been described ${ }^{[77]}$. Even in the most common scenario of mixed pathology, the question arises as to whether it represents $\mathrm{DLB}$ with some degree of $\mathrm{AD}$ pathology, $\mathrm{AD}$ with some degree of Lewy-pathology or equally severe pathology of both types ${ }^{[58]}$. Similarly, in a patient with a FTD-like clinical picture, the identification of the typical AD CSF signature may serve as exclusion criterion for $\mathrm{FTD}^{[78]}$, suggesting $\mathrm{AD}$ with an atypical clinical presentation (frontal variant) ${ }^{[11]}$, but mixed pathology cannot be excluded, since patients with concomitant FTD and AD do exist ${ }^{[79]}$.

Some patients may show borderline or gray-zone levels in one or more of the classical biomarkers. The $\tau_{\mathrm{T}} / \mathrm{A} \beta_{42}$ and $\tau_{\mathrm{P}-181} / \mathrm{A} \beta_{42}$ ratios may be of some help in such patients ${ }^{[12]}$, but not always. The "Erlangen Score", 
which depends on normal, border-zone or abnormal biomarker levels, has been suggested to determine the level of neurochemical probability for (or against) $\mathrm{AD}$ in both dementia ${ }^{[80]}$ and pre-dementia stages ${ }^{[81]}$.

In case of atypical, conflicting or inconclusive CSF biomarker results, other neurochemical and/or imaging biomarkers, and/or later repetition of CSF sampling and analysis may be necessary ${ }^{[50]}$.

\section{VARIABILITY OF BIOMARKER RESULTS}

Despite intensive research, there is still a significant inter- and intra-laboratory variability in the results of biomarker level determination, as a result of pre-analytical, analytical, post-analytical and kit-related factors, even between laboratories using the same methods ${ }^{[82-86]}$. During the last decade, various international initiatives, quality control programs and international workshops have been organized to reduce variability and harmonize the levels of biomarkers ${ }^{[67,82,83]}$, including the "Biomarkers for Alzheimer's disease and Parkinson's disease" project of the Joint Programming Neurodegenerative Disease (JPNDBIOMARKAPD $)^{[87]}$. As a result, recommendations have been published regarding lumbar puncture, pre-analytical and analytical standardized operating procedures ${ }^{[82,88-90]}$, leading to improvement in diagnostic performance and reduction of measurement errors ${ }^{[91]}$. Although a measurement error of $\pm 20 \%$ in only one of the three biomarkers may have a minimal effect on overall diagnostic performance in everyday practice (variability $\leq 8 \%$ ), errors of greater magnitude and/or affecting more than one biomarker, may lead to a significant decrease in diagnostic accuracy ${ }^{[92]}$. Newer methods for the determination of classical biomarkers may show better repeatability and reproducibility and less inter-laboratory variability ${ }^{[6,93]}$.

\section{NEW AND EMERGING BIOMARKERS FOR AD AND OTHER DISORDERS}

Among many molecules studied in AD, neurogranin, neurofilament light (NFL), the ectodomain of triggering receptor expressed on myeloid cells 2 (sTREM2) and visinin-like protein 1 (VILIP-1) may serve as markers of synaptic loss, neuronal/axonal damage, microglial activation and neurodegeneration, respectively ${ }^{[66-68]}$.

Recently, promising results have been published for CSF TDP-43 in patients with FTD and/or amyotrophic lateral sclerosis $(\mathrm{ALS})^{[94-96]}$. The $\tau_{\mathrm{P}-181} / \tau_{\mathrm{T}}$ ratio has been suggested as another marker, which may prove helpful in the identification of FTD pathology ${ }^{[97]}$, but its combination with TDP-43 may increase its diagnostic value even more ${ }^{[95]}$. NFL may also have some value in patients with FTD and/or ALS ${ }^{[66]}$. Further studies are needed, and they are in progress, both for validation and standardization of TDP-43 methods and for identifying the optimum combination of TDP-43 with other biomarkers for in vivo detection of the FTD subtype.

Alpha-synuclein ( $\alpha$-syn) has been studied as a biomarker of Lewy body synucleinopathies, in the differential diagnosis of cognitive and/or movement disorders ${ }^{[98,99]}$. Several studies have revealed that in synucleinopathies such as DLB, CSF $\alpha$-syn levels are reduced, as compared to controls or $\mathrm{AD}^{[100,101]}$. However, increased levels in $\mathrm{DLB} v \boldsymbol{v} . \mathrm{AD}^{[102]}$ or $\mathrm{PDD}^{[103]}$ have also been reported, especially of oligomeric $\alpha-$ syn $^{[104]}$, while for PD or PDD, a non-significant reduction was too small to achieve diagnostic significance vs. controls and other movement disorders ${ }^{[13]}$ or $\mathrm{AD}^{[103]}$. The above discrepancies indicate that, despite intensive research, there are methodological problems in $\alpha$-syn quantification. Determination of $\alpha$-syn needs strict pre-analytical control for confounding factors (especially bloody CSF), while assay parameters such as antibodies used, and forms of $\alpha$-syn detected, necessitate further studies before one or more robust tests become widely acceptable ${ }^{[99,105]}$.

\section{CONCLUDING REMARKS}

Classical CSF biomarkers of AD are useful tools in the (differential) diagnosis of patients with cognitive decline, especially in early or atypical cases [Table 1]. They are useful in differentiating AD from normal 
Table 1. Levels of classical cerebrospinal fluid Alzheimer's disease biomarkers in various cognitive disorders

\begin{tabular}{llll}
\hline & \multicolumn{1}{c}{$\mathbf{A} \beta_{\mathbf{4 2}}$ or $\mathbf{A} \beta_{\mathbf{4 2}} / \mathbf{A} \beta_{\mathbf{4 0}}$} & Total tau $\left(_{\boldsymbol{T}}\right.$ ) & Phospho-tau \\
\hline Alzheimer's disease & Decreased & Increased & Increased \\
Vascular cognitive impairment & May be decreased in some patients & May be increased in some patients & Normal \\
Frontotemporal dementia & May rarely be decreased & May be increased in some patients & May be increased in some patients \\
Dementia with Lewy bodies & Frequently decreased & May be increased in some patients & Normal \\
Creutzfeldt-Jakob disease & May be decreased in some patients Extremely increased & Normal \\
Normal aging & Normal & Normal & Normal \\
Psychiatric disorders & Normal & Normal & Normal \\
\hline
\end{tabular}

Based on the references cited throughout the text. *Usually for $\tau_{\mathrm{P}-181}$, others have also been suggested

aging, psychiatric disorders such as depression, pure vascular cognitive impairment, pure DLB and FTD, and they can identify atypical and misleading clinical presentations of $\mathrm{AD}$, or the coexistence of $\mathrm{AD}$ in other primary (such as VCI or DLB) or secondary cognitive disorders ${ }^{[12,14,44,54,56-59]}$. However, they should always be used in combination with clinical, neuropsychological and imaging data ${ }^{[15]}$, and due to variability of measurements, each laboratory should establish their own normal or cut-off values ${ }^{[66]}$.

CSF biomarkers detect normal or abnormal biochemistry, offering (during life) an alternative to postmortem pathology and showing a very good concordance with pathological diagnosis ${ }^{[66]}$. Thus, many, if not most, of patients can be correctly diagnosed. However, borderline or inconclusive results may occur in some patients, requiring repetition of measurements and/or use of additional biomarkers ${ }^{[50,96,102]}$. Furthermore, classical CSF biomarkers cannot accurately detect mixed degenerative pathologies, which are not unusual in older patients. For example, the identification of an AD biomarker profile in a patient with dementia, parkinsonism and hallucinations, may indicate an atypical clinical presentation of $\mathrm{AD}, \mathrm{AD}$ with some additional Lewy bodies, DLB with some additional AD-type pathology, or a severe degree of both pathologies ${ }^{[58]}$. This further necessitates the use of additional biomarkers (in the above case, $\alpha$-syn). Unfortunately, methodological issues requiring further investigation prevent some of the newer biomarkers such as $\alpha$-syn and TDP-43 to be currently considered "established".

The 3 classical AD biomarkers $\left(\tau_{\mathrm{T}}, \mathrm{A} \beta_{42}\right.$ and $\left.\tau_{\mathrm{P}-181}\right)$ become 4 by adding $\mathrm{A} \beta_{40}$. Adding NFL, $\alpha$-syn, TDP-43 and others increases the number to at least 7 . Adding them to structural and functional neuroimaging and possibly to genetic biomarkers, leads to a tempting increase of available data for patients; unfortunately, there is an even more substantial increase in cost, while the diagnostic accuracy may not be equally increased in some patients. Instead of an "all for all" approach, a personalized, precision medicine approach may be more appropriate ${ }^{[106]}$, while blood biomarkers may be adequate for some patients ${ }^{[107]}$.

The ability to detect the AD CSF biochemical signature in pre-dementia and especially in pre-symptomatic subjects, raises some ethical issues ${ }^{[108]}$. Communication of a positive result in a non-demented subject may have adverse effects in quality of life and trigger significant emotional reactions ${ }^{[109]}$. Since the time of appearance of the initial vague symptom(s) is usually unpredictable, many authorities consider it inappropriate to perform such diagnostic tests in the majority of asymptomatic subjects (including families with autosomal dominant AD). However, other subjects prefer disclosure of the results, so that they can adjust their life accordingly (including measures for secondary prevention) or make important decisions before dementia affects their judgment ${ }^{[110]}$. Such parameters should be taken into consideration before determining CSF biomarkers and/or communicating results, especially in research settings ${ }^{[108]}$.

On the other hand, early detection is important in correct classification of subjects in trials of diseasemodifying approaches, which may be effective when given in pre-symptomatic stages of AD. Since such trials are usually multicenter, stability, robustness and harmonization of methods and results, regulatory guidance, operator training, quality control programs, strict adherence to recommendations for 
standardized operating procedures and harmonization of diagnostic criteria used, as well as well-organized and secure patient data sharing, are all required and pose challenges that should be faced by specialized centers $^{[111]}$.

\section{DECLARATIONS}

\section{Authors' contributions}

The author contributed solely to the article.

\section{Availability of data and materials}

Not applicable.

\section{Financial support and sponsorship}

None.

\section{Conflicts of interest}

The author declared that there are no conflicts of interest.

\section{Ethical approval and consent to participate}

Not applicable.

\section{Consent for publication}

Not applicable.

\section{Copyright}

(c) The Author(s) 2020.

\section{REFERENCES}

1. Pierce AL, Bullain SS, Kawas CH. Late-onset Alzheimer disease. Neurol Clin 2017;35:283-93.

2. Wallin A, Román GC, Esiri M, Kettunen P, Svensson J, et al. Update on vascular cognitive impairment associated with subcortical smallvessel disease. J Alzheimers Dis 2018;62:1417-41.

3. Galasko D. Lewy body disorders. Neurol Clin 2017;35:325-38.

4. Karageorgiou E, Miller BL. Frontotemporal lobar degeneration: a clinical approach. Semin Neurol 2014;34:189-201.

5. McKhann G, Drachman D, Folstein M, Katzman R, Price D, et al. Clinical diagnosis of Alzheimer's disease: report of the NINCDSADRDA Work Group under the auspices of Department of Health and Human Services Task Force on Alzheimer's Disease. Neurology 1984;34:939-44.

6. Lopez OL, Becker JT, Klunk W, Saxton J, Hamilton RL, et al. Research evaluation and diagnosis of probable Alzheimer's disease over the last two decades: I. Neurology 2000;55:1854-62.

7. Risse SC, Raskind MA, Nochlin D, Sumi SM, Lampe TH, et al. Neuropathological findings in patients with clinical diagnoses of probable Alzheimer's disease. Am J Psychiatry 1990;147:168-71.

8. Mendez M, Mastri AR, Sung JH, Frey WH. Clinically diagnosed Alzheimer's disease: neuropathologic findings in 650 cases. Alzheimer Dis Assoc Disord 1992;6:35-43.

9. Gilleard CJ, Kellett JM, Coles JA, Millard PH, Honavar M, et al. The St. George's dementia bed investigation study: a comparison of clinical and pathological diagnosis. Acta Psychiatr Scand 1992;85:264-69.

10. McKhann GM, Knopman DS, Chertkow H, Hyman BT, Jack CR Jr, et al. The diagnosis of dementia due to Alzheimer's disease: recommendations from the National Institute on Aging-Alzheimer's Association workgroups on diagnostic guidelines for Alzheimer's disease. Alzheimers Dement 2011;7:263-69.

11. Dubois B, Feldman HH, Jacova C, Hampel H, Molinuevo JL, et al. Advancing research diagnostic criteria for Alzheimer's disease: the IWG-2 criteria. Lancet Neurol 2014;13:614-29.

12. Paraskevas GP, Kaselimis D, Kourtidou E, Constantinides V, Bougea A, et al. Cerebrospinal fluid biomarkers as a diagnostic tool of the underlying pathology of primary progressive aphasia. J Alzheimers Dis 2017;55:1453-61.

13. Constantinides VC, Paraskevas GP, Emmanouilidou E, Petropoulou O, Bougea A, et al. CSF biomarkers $\beta$-amyloid, tau proteins and a-synuclein in the differential diagnosis of Parkinson-plus syndromes. J Neurol Sci 2017;382:91-5.

14. Constantinides VC, Paraskevas GP, Efthymiopoulou E, Stefanis L, Kapaki E. Clinical, neuropsychological and imaging characteristics of 
Alzheimer's disease patients presenting as corticobasal syndrome. J Neurol Sci 2019;398:142-7.

15. Paraskevas GP, Constantinides VC, Pyrgelis ES, Kapaki E. Mixed small vessel disease in a patient with dementia with Lewy bodies. Brain Sci 2019;9:E159.

16. Wallin A, Nordlund A, Jonsson M, Blennow K, Zetterberg H, et al. Alzheimer's disease-subcortical vascular disease spectrum in a hospital-based setting: Overview of results from the Gothenburg MCI and dementia studies. J Cereb Blood Flow Metab 2016;36:95-113.

17. Peavy GM, Edland SD, Toole BM, Hansen LA, Galasko DR, et al. Phenotypic differences based on staging of Alzheimer's neuropathology in autopsy-confirmed dementia with Lewy bodies. Parkinsonism Relat Disord 2016;31:72-8.

18. van der Zande JJ, Steenwijk MD, Ten Kate M, Wattjes MP, Scheltens P, et al. Gray matter atrophy in dementia with Lewy bodies with and without concomitant Alzheimer's disease pathology. Neurobiol Aging 2018;71:171-8.

19. Savica R, Beach TG, Hentz JG, Sabbagh MN, Serrano GE, et al. Lewy body pathology in Alzheimer's disease: A clinicopathological prospective study. Acta Neurol Scand 2019;139:76-81.

20. Lemstra AW, de Beer MH, Teunissen CE, Schreuder C, Scheltens P, et al. Concomitant AD pathology affects clinical manifestation and survival in dementia with Lewy bodies. J Neurol Neurosurg Psychiatry 2017;88:113-8.

21. Bennett D, Schneider J, Bienias J, Evans DA, Wilson RS. Mild cognitive impairment is related to Alzheimer pathology and cerebral infarctions. Neurology 2005;64:834-41.

22. Galasko D, Hansen LA, Katzman R, Wiederholt W, Masliah E, et al. Clinical-neuropathological correlations in Alzheimer's disease and related dementias. Arch Neurol 1994;51:888-95.

23. Johnell K, Religa D, Eriksdotter M. Differences in drug therapy between dementia disorders in the Swedish dementia registry: a nationwide study of over 7,000 patients. Dement Geriatr Cogn Disord 2013;35:239-48.

24. Jellinger KA, Bancher C. Neuropathology of Alzheimer's disease: a critical update. J Neural Transm Suppl 1998;54:77-95.

25. Bancher C, Paulus W, Paukner K, Jellinger K. Neuropathologic diagnosis of Alzheimer disease: consensus between practicing neuropathologists? Alzheimer Dis Assoc Disord 1997;11:207-19.

26. Forloni G. beta-Amyloid neurotoxicity. Funct Neurol 1993;8:211-25.

27. Iqbal K, Alonso A, Gong C, Khatoon S, Kudo T, et al. Molecular pathology of Alzheimer neurofibrillary degeneration. Acta Neurobiol Exp (Wars) 1993;53:325-35.

28. Choi BH. Oxidative stress and Alzheimer's disease. Neurobiol Aging 1995;16:675-8.

29. Smith-Swintosky VL, Mattson MP. Glutamate, beta-amyloid precursor proteins, and calcium mediated neurofibrillary degeneration. J Neural Transm Suppl 1994;44:29-45.

30. Stege GJ, Bosman GJ. The biochemistry of Alzheimer's disease. Drugs Aging 1999;14:437-46.

31. Gonzalez B, Abud EM, Abud AM, Poon WW, Gylys KH. Tau spread, apolipoprotein e, inflammation, and more: rapidly evolving basic science in Alzheimer disease. Neurol Clin 2017;35:175-90.

32. Rietdijk CD, van Wezel RJA, Garssen J, Kraneveld AD. Neuronal toll-like receptors and neuro-immunity in Parkinson's disease, Alzheimer's disease and stroke. Neuroimmunol Neuroinflammation 2016;3:27-37.

33. Burns LH, Wang HY. Altered filamin A enables amyloid beta-induced tau hyperphosphorylation and neuroinflammation in Alzheimer's disease. Neuroimmunol Neuroinflammation 2017;4:263-71.

34. Rentzos M, Zoga M, Paraskevas GP, Kapaki E, Rombos A, et al. IL-15 is elevated in cerebrospinal fluid of patients with Alzheimer's disease and frontotemporal dementia. J Geriatr Psychiatry Neurol 2006;19:114-7.

35. Vandermeeren M, Mercken M, Vanmechelen E, Six J, van de Voorde A, et al. Detection of tau proteins in normal and Alzheimer's disease cerebrospinal fluid with a sensitive sandwich enzyme-linked immunosorbent assay. J Neurochem 1993;61:1828-34.

36. Vanmechelen E, Vanderstichele H, Davidsson P, Van Kerschaver E, Van Der Perre B, et al. Quantification of tau phosphorylated at threonine 181 in human cerebrospinal fluid: a sandwich ELISA with a synthetic phosphopeptide for standardization. Neurosci Lett 2000;285:49-52.

37. Vanderstichele H, Van Kerschaver E, Hesse C, Davidsson P, Buyse MA, et al. Standardization of measurement of beta-amyloid(1-42) in cerebrospinal fluid and plasma. Amyloid 2000;7:245-58.

38. Blennow K, Wallin A, Agren H, Spenger C, Siegfried J, et al. Tau protein in cerebrospinal fluid: a biochemical marker for axonal degeneration in Alzheimer disease? Mol Chem Neuropathol 1995;26:231-45.

39. Vanderstichele H, De Vreese K, Blennow K, Andreasen N, Sindic C, et al. Analytical performance and clinical utility of the INNOTEST PHOSPHO-TAU181P assay for discrimination between Alzheimer's disease and dementia with Lewy bodies. Clin Chem Lab Med 2006;44:1472-80.

40. Sjögren M, Minthon L, Davidsson P, Granérus AK, Clarberg A, et al. CSF levels of tau, beta-amyloid(1-42) and GAP-43 in frontotemporal dementia, other types of dementia and normal aging. J Neural Transm (Vienna) 2000;107:563-79.

41. Paraskevas GP, Kapaki E, Liappas I, Theotoka I, Mamali I, et al. The diagnostic value of cerebrospinal fluid tau protein in dementing and nondementing neuropsychiatric disorders. J Geriatr Psychiatry Neurol 2005;18:163-73.

42. Hulstaert F, Blennow K, Ivanoiu A, Schoonderwaldt HC, Riemenschneider M, et al. Improved discrimination of AD patients using betaamyloid(1-42) and tau levels in CSF. Neurology 1999;52:1555-62.

43. Kapaki E, Paraskevas GP, Zalonis I, Zournas C. CSF tau protein and beta-amyloid (1-42) in Alzheimer's disease diagnosis: discrimination from normal ageing and other dementias in the Greek population. Eur J Neurol 2003;10:119-28.

44. Paraskevas GP, Kapaki E, Papageorgiou SG, Kalfakis N, Andreadou E, et al. CSF biomarker profile and diagnostic value in vascular dementia. Eur J Neurol 2009;16:205-11.

45. Jack CR Jr, Holtzman DM. Biomarker modeling of Alzheimer's disease. Neuron 2013;80:1347-58. 
46. Fagan AM, Xiong C, Jasielec MS, Bateman RJ, Goate AM, et al. Longitudinal change in CSF biomarkers in autosomal-dominant Alzheimer's disease. Sci Transl Med 2014;6:226ra30.

47. Buchhave P, Minthon L, Zetterberg H, Wallin AK, Blennow K, et al. Cerebrospinal fluid levels of $\beta$-amyloid 1-42, but not of tau, are fully changed already 5 to 10 years before the onset of Alzheimer dementia. Arch Gen Psychiatry 2012;69:98-106.

48. Park JE, Choi KY, Kim BC, Choi SM, Song MK, et al. Cerebrospinal fluid biomarkers for the diagnosis of prodromal Alzheimer's disease in amnestic mild cognitive impairment. Dement Geriatr Cogn Dis Extra 2019;9:100-13.

49. Buchhave P, Blennow K, Zetterberg H, Stomrud E, Londos E, et al. Longitudinal study of CSF biomarkers in patients with Alzheimer's disease. PLoS One 2009;4:e6294.

50. Simonsen AH, Herukka SK, Andreasen N, Baldeiras I, Bjerke M, et al. Recommendations for CSF AD biomarkers in the diagnostic evaluation of dementia. Alzheimers Dement 2017;13:274-84.

51. Hansson O, Zetterberg H, Buchhave P, Londos E, Blennow K, et al. Association between CSF biomarkers and incipient Alzheimer's disease in patients with mild cognitive impairment: a follow-up study. Lancet Neurol 2006;5:228-34.

52. Engelborghs S, De Vreese K, Van de Casteele T, Vanderstichele H, Van Everbroeck B, et al. Diagnostic performance of a CSF-biomarker panel in autopsy-confirmed dementia. Neurobiol Aging 2008;29:1143-59.

53. Seeburger JL, Holder DJ, Combrinck M, Joachim C, Laterza O, et al. Cerebrospinal fluid biomarkers distinguish postmortem-confirmed Alzheimer's disease from other dementias and healthy controls in the OPTIMA cohort. J Alzheimers Dis 2015;44:525-39.

54. Kapaki E, Liappas I, Paraskevas GP, Theotoka I, Rabavilas A. The diagnostic value of tau protein, beta-amyloid (1-42) and their ratio for the discrimination of alcohol-related cognitive disorders from Alzheimer's disease in the early stages. Int J Geriatr Psychiatry 2005;20:722-9.

55. Le Bastard N, Martin JJ, Vanmechelen E, Vanderstichele H, De Deyn PP, et al. Added diagnostic value of CSF biomarkers in differential dementia diagnosis. Neurobiol Aging 2010;31:1867-76.

56. Kapaki E, Paraskevas GP, Papageorgiou SG, Bonakis A, Kalfakis N, et al. Diagnostic value of CSF biomarker profile in frontotemporal lobar degeneration. Alzheimer Dis Assoc Disord 2008;22:47-53.

57. Wallin A, Kapaki E, Boban M, Engelborghs S, Hermann DM, et al. Biochemical markers in vascular cognitive impairment associated with subcortical small vessel disease - A consensus report. BMC Neurol 2017;17:102.

58. Paraskevas GP, Bougea A, Constantinides VC, Bourbouli M, Petropoulou O, et al. In vivo prevalence of Alzheimer biomarkers in dementia with Lewy bodies. Dement Geriatr Cogn Disord 2019;47:289-96.

59. Kapaki EN, Paraskevas GP, Tzerakis NG, Sfagos C, Seretis A, et al. Cerebrospinal fluid tau, phospho-tau181 and beta-amyloid1-42 in idiopathic normal pressure hydrocephalus: a discrimination from Alzheimer's disease. Eur J Neurol 2007;14:168-73.

60. Ossenkoppele R, Mattsson N, Teunissen CE, Barkhof F, Pijnenburg Y, et al. Cerebrospinal fluid biomarkers and cerebral atrophy in distinct clinical variants of probable Alzheimer's disease. Neurobiol Aging 2015;36:2340-47.

61. The Ronald and Nancy Reagan Research Institute of the Alzheimer's Association and the National Institute on Aging Working Group. Consensus report of the working Group on: "Molecular and Biochemical Markers of Alzheimer's Disease". Neurobiol Aging 1998;19:109-16.

62. Andreasen N, Minthon L, Davidsson P, Vanmechelen E, Vanderstichele H, et al. Evaluation of CSF-tau and CSF-Abeta42 as diagnostic markers for Alzheimer disease in clinical practice. Arch Neurol 2001;58:373-9.

63. Waldemar G, Dubois B, Emre M, Georges J, McKeith IG, et al. Recommendations for the diagnosis and management of Alzheimer's disease and other disorders associated with dementia: EFNS guideline. Eur J Neurol 2007;14:e1-26.

64. Albert MS, DeKosky ST, Dickson D, Dubois B, Feldman HH, et al. The diagnosis of mild cognitive impairment due to Alzheimer's disease: recommendations from the National Institute on Aging-Alzheimer's Association workgroups on diagnostic guidelines for Alzheimer's disease. Alzheimers Dement 2011;7:270-9.

65. Sperling RA, Aisen PS, Beckett LA, Bennett DA, Craft S, et al. Toward defining the preclinical stages of Alzheimer's disease: recommendations from the National Institute on Aging-Alzheimer's Association workgroups on diagnostic guidelines for Alzheimer's disease. Alzheimers Dement 2011;7:280-92.

66. Lewczuk P, Riederer P, O'Bryant SE, Verbeek MM, Dubois B, et al. Cerebrospinal fluid and blood biomarkers for neurodegenerative dementias: An update of the Consensus of the Task Force on Biological Markers in Psychiatry of the World Federation of Societies of Biological Psychiatry. World J Biol Psychiatry 2018;19:244-328.

67. Blennow K, Zetterberg H. The past and the future of Alzheimer's disease fluid biomarkers. J Alzheimers Dis 2018;62:1125-40.

68. Molinuevo JL, Ayton S, Batrla R, Bednar MM, Bittner T, et al. Current state of Alzheimer's fluid biomarkers. Acta Neuropathol 2018;136:821-53.

69. Isaac M, Vamvakas S, Abadie E, Jonsson B, Gispen C, et al. Qualification opinion of novel methodologies in the predementia stage of Alzheimer's disease: cerebro-spinal-fluid related biomarkers for drugs affecting amyloid burden-regulatory considerations by European Medicines Agency focusing in improving benefit/risk in regulatory trials. Eur Neuropsychopharmacol 2011;21:781-8.

70. Cavedo E, Lista S, Khachaturian Z, Aisen P, Amouyel P, et al. The road ahead to cure Alzheimer's disease: development of biological markers and Neuroimaging methods for prevention trials across all stages and target populations. J Prev Alzheimers Dis 2014;1:181-202.

71. Jack CR Jr. PART and SNAP. Acta Neuropathol 2014;128:773-6.

72. Lewczuk P, Lelental N, Spitzer P, Maler JM, Kornhuber J. Amyloid b 42/40 CSF concentration ratio in the diagnostics of Alzheimer's disease: validation of two novel assays. J Alzheimers Dis 2015;43:183-91.

73. Jack CR Jr, Knopman DS, Chételat G, Dickson D, Fagan AM, et al. Suspected non-Alzheimer disease pathophysiology-concept and controversy. Nat Rev Neurol 2016;12:117-24. 
74. Jack CR Jr, Bennett DA, Blennow K, Carrillo MC, Dunn B, et al. NIA-AA Research Framework: Toward a biological definition of Alzheimer's disease. Alzheimers Dement 2018;14:535-62.

75. van Steenoven I, Aarsland D, Weintraub D, Londos E, Blanc F, et al. Cerebrospinal fluid Alzheimer's disease biomarkers across the spectrum of Lewy body diseases: results from a large multicenter cohort. J Alzheimers Dis 2016;54:287-95.

76. McKeith IG, Boeve BF, Dickson DW, Halliday G, Taylor JP, et al. Diagnosis and management of dementia with Lewy bodies: Fourth consensus report of the DLB Consortium. Neurology 2017;89:88-100.

77. Skogseth R, Hortobágyi T, Soennesyn H, Chwiszczuk L, Ffytche D, et al. Accuracy of clinical diagnosis of dementia with Lewy bodies versus neuropathology. J Alzheimers Dis 2017;59:1139-52.

78. Rascovsky K, Hodges JR, Knopman D, Mendez MF, Kramer JH, et al Sensitivity of revised diagnostic criteria for the behavioural variant of frontotemporal dementia. Brain 2011;134:2456-77.

79. Lleó A, Irwin DJ, Illán-Gala I, McMillan CT, Wolk DA, et al. A 2-Step Cerebrospinal algorithm for the selection of frontotemporal lobar degeneration subtypes. JAMA Neurol 2018;75:738-45.

80. Lewczuk P, Zimmermann R, Wiltfang J, Kornhuber J. Neurochemical dementia diagnostics: a simple algorithm for interpretation of the CSF biomarkers. J Neural Transm 2009;116:1163-7.

81. Lewczuk P, Kornhuber J, Toledo JB, Trojanowski JQ, Knapik-Czajka M, et al. Validation of the Erlangen score algorithm for the prediction of the development of dementia due to Alzheimer's disease in pre-dementia subjects. J Alzheimers Dis 2015;48:433-41.

82. Teunissen CE, Verwey NA, Kester MI, van Uffelen K, Blankenstein MA. Standardization of assay procedures for analysis of the CSF biomarkers amyloid $\beta(1-42)$, tau, and phosphorylated tau in Alzheimer's disease: report of an international workshop. Int J Alzheimers Dis 2010;2010:635053.

83. Mattsson N, Andreasson U, Persson S, Arai H, Batish SD, et al. The Alzheimer's Association external quality control program for cerebrospinal fluid biomarkers. Alzheimers Dement 2011;7:386-95.e6.

84. Kang JH, Korecka M, Toledo JB, Trojanowski JQ, Shaw LM. Clinical utility and analytical challenges in measurement of cerebrospinal fluid amyloid- $\beta(1-42)$ and $\tau$ proteins as Alzheimer disease biomarkers. Clin Chem 2013;59:903-16.

85. Mattsson N, Andreasson U, Persson S, Carrillo MC, Collins S, et al.; Alzheimer's Association QC Program Work Group. CSF biomarker variability in the Alzheimer's Association quality control program. Alzheimers Dement 2013;9:251-61.

86. Vos SJ, Visser PJ, Verhey F, Aalten P, Knol D, et al. Variability of CSF Alzheimer's disease biomarkers: implications for clinical practice. PLoS One 2014;9:e100784.

87. Biomarkers for Alzheimer's disease and Parkinson's disease project of the Joint Programming Neurodegenerative Disease (JPNDBIOMARKAPD) 2012. Available from: http://www.neurodegenerationresearch.eu/fileadmin/Project_Fact_Sheets/PDFs/Biomarkers/ BIOMARKAPD_Fact_Sheet_Template.pdf [Last accessed on 15 May 2020]

88. Engelborghs S, Niemantsverdriet E, Struyfs H, Blennow K, Brouns R, et al. Consensus guidelines for lumbar puncture in patients with neurological diseases. Alzheimers Dement 2017;8:111-26.

89. del Campo M, Mollenhauer B, Bertolotto A, Engelborghs S, Hampel H, et al. Recommendations to standardize preanalytical confounding factors in Alzheimer's and Parkinson's disease cerebrospinal fluid biomarkers: an update. Biomark Med 2012;6:419-30.

90. Le Bastard N, De Deyn PP, Engelborghs S. Importance and impact of preanalytical variables on Alzheimer disease biomarker concentrations in cerebrospinal fluid. Clin Chem 2015;61:734-43.

91. Bourbouli M, Kapaki E, Petropoulou O, Paraskevas GP. Improved Performance of CSF dementia biomarker measurements over time: the effect of quality control and harmonization programs. Biomark Applic 2018:BMAP-126.

92. Niemantsverdriet E, Goossens J, Struyfs H, Martin JJ, Goeman J, et al. Diagnostic impact of cerebrospinal fluid biomarker (pre-) analytical variability in Alzheimer's disease. J Alzheimers Dis 2016;51:97-106.

93. Lifke V, Kollmorgen G, Manuilova E, Oelschlaegel T, Hillringhaus L, et al. Elecsys ${ }^{\circledR}$ Total-Tau and Phospho-Tau (181P) CSF assays: analytical performance of the novel, fully automated immunoassays for quantification of tau proteins in human cerebrospinal fluid. Clin Biochem 2019;72:30-8.

94. Junttila A, Kuvaja M, Hartikainen P, Siloaho M, Helisalmi S, et al. Cerebrospinal fluid TDP-43 in frontotemporal lobar degeneration and amyotrophic lateral sclerosis patients with and without the C9ORF72 hexanucleotide expansion. Dement Geriatr Cogn Dis Extra 2016;6:142-9.

95. Bourbouli M, Rentzos M, Bougea A, Zouvelou V, Constantinides VC, et al. Cerebrospinal fluid TAR DNA-binding protein 43 combined with Tau proteins as a candidate biomarker for amyotrophic lateral sclerosis and frontotemporal dementia spectrum disorders. Dement Geriatr Cogn Disord 2017;44:144-52.

96. Paraskevas GP, Bourbouli M, Zaganas I, Kapaki E. The emerging TDP-43 proteinopathy. Neuroimmunol Neuroinflammation $2018 ; 5: 17$.

97. Pijnenburg YA, Verwey NA, van der Flier WM, Scheltens P, Teunissen CE. Discriminative and prognostic potential of cerebrospinal fluid phosphoTau/tau ratio and neurofilaments for frontotemporal dementia subtypes. Alzheimers Dementia 2015;1:505-12.

98. Mollenhauer B, El-Agnaf OM, Marcus K, Trenkwalder C, Schlossmacher MG. Quantification of alpha-synuclein in cerebrospinal fluid as a biomarker candidate: review of the literature and considerations for future studies. Biomark Med 2010;4:683-99.

99. Schade S, Mollenhauer B. Biomarkers in biological fluids for dementia with Lewy bodies. Alzheimers Res Ther 2014;6:72.

100. Laske C, Fallgatter AJ, Stransky E, Hagen K, Berg D, et al. Decreased $\alpha$-synuclein serum levels in patients with Lewy body dementia compared to Alzheimer's disease patients and control subjects. Dement Geriatr Cogn Disord 2011;31:413-6.

101. Aarsland D, Kurz M, Beyer M, Bronnick K, Piepenstock Nore S, et al. Early discriminatory diagnosis of dementia with Lewy bodies. The emerging role of CSF and imaging biomarkers. Dement Geriatr Cogn Disord 2008;25:195-205.

102. Kapaki E, Paraskevas GP, Emmanouilidou E, Vekrellis K. The diagnostic value of CSF alpha-synuclein in the differential diagnosis of 
dementia with Lewy bodies vs. normal subjects and patients with Alzheimer's disease. PLoS One 2013;8:e81654.

103. Bougea A, Stefanis L, Paraskevas GP, Emmanouilidou E, Efthymiopoulou E, et al. Neuropsychiatric symptoms and $\alpha$-Synuclein profile of patients with Parkinson's disease dementia, dementia with Lewy bodies and Alzheimer's disease. J Neurol 2018;265:2295-301.

104. Hansson O, Hall S, Ohrfelt A, Zetterberg H, Blennow K, et al. Levels of cerebrospinal fluid $\alpha$-synuclein oligomers are increased in Parkinson's disease with dementia and dementia with Lewy bodies compared to Alzheimer's disease. Alzheimers Res Ther 2014;6:25.

105. Simonsen AH, Kuiperij B, El-Agnaf OM, Engelborghs S, Herukka SK, et al. The utility of alpha-synuclein as biofluid marker in neurodegenerative diseases: a systematic review of the literature. Biomark Med 2016;10:19-34.

106. Hampel H, O’Bryant SE, Castrillo JI, Ritchie C, Rojkova K, et al. Precision medicine - the golden gate for detection, treatment and prevention of Alzheimer's disease. J Prev Alzheimers Dis 2016;3:243-59.

107. Hampel H, O'Bryant SE, Molinuevo JL, Zetterberg H, Masters CL, et al. Blood-based biomarkers for Alzheimer disease: mapping the road to the clinic. Nat Rev Neurol 2018;14:639-52.

108. Milne R, Bunnik E, Diaz A, Richard E, Badger S, et al. Perspectives on communicating biomarker-based assessments of Alzheimer's disease to cognitively healthy individuals. J Alzheimers Dis 2018;62:487-98.

109. Bunnik EM, Richard E, Milne R, Schermer MHN. On the personal utility of Alzheimer's disease-related biomarker testing in the research context. J Med Ethics 2018;44:830-4.

110. Milne R, Diaz A, Badger S, Bunnik E, Fauria K, et al. At, with and beyond risk: expectations of living with the possibility of future dementia. Sociol Health Illn 2018;40:969-87.

111. Arnerić SP, Batrla-Utermann R, Beckett L, Bittner T, Blennow K, et al. Cerebrospinal fluid biomarkers for Alzheimer's disease: a view of the regulatory science qualification landscape from the coalition against major diseases CSF biomarker team. J Alzheimers Dis 2017;55:19-35. 